\title{
Kinetic Resolution of Optically Pure 3-Alkanol by Pseudomonas cepacia Lipase-Catalyzed Transesterification with Vinyl Acetate in Organic Solvent
}

\author{
Hirofumi Hirata $^{1 *}$, Masako IKushima ${ }^{1}$, Michitoshi WATANabe $^{1}, \operatorname{Keiyo~Kawauchi~}^{1}$, \\ Masato Miyagishi ${ }^{1}$, Yun-Gang Chen $^{2}$ and Hiroshi Yanagishita ${ }^{3}$ \\ ${ }^{1}$ Department of Bioscience and Technology, School of Engineering, Hokkaido Tokai University \\ (5-1 Minamisawa, Minami-ku, Sapporo 005-8601, JAPAN) \\ ${ }^{2}$ Research Institute of Higher Education Programs, Hokkaido Tokai University \\ (5-1 Minamisawa, Minami-ku, Sapporo 005-8601, JAPAN) \\ ${ }^{3}$ AIST Tsukuba Central 5, National Institute of Advanced Industrial Science and Technology \\ (1-1 Higashi, Tsukuba 305-8565, JAPAN)
}

Edited by Y. Shimada, Osaka Mun. Tec. Res. Inst., and accepted March 25, 2003 (received for review January 10, 2003)

\begin{abstract}
Kinetic resolution of 3-alkanol by Pseudomonas cepacia lipase-catalyzed transesterification has been studied using vinyl acetate as an acetylating reagent, five alcohols and different organic solvents. The optical resolution data did not fit the previously reported theory: the enantioselectivity ( $E$ : the enantiomeric ratio for the homocompetitive reaction) showed the maxima against the extent of conversion $(c)$ in all systems studied. The optical resolution of $(S)$-3-alkanol with above $95 \%$ of enantiomeric excess $(e e)$ was attained by controlling $c$, but only a moderate ee was observed in the resolution of $(R)$ isomer from the racemate, owing to low or moderate enantioselectivity. The resolution of enantiomers with high optical purity was carried out using enantiomerically enriched alcohol: the ee values of the resolved alcohols showed an excellent agreement with those determined by the previously reported equations using the optical resolution data. Based on these observations, optically pure $(R)$ - and $(S)$-3-alkanols (ee $\geqq 99 \%$ ) were resolved from the racemates in a preparative scale by repeating the transesterification.
\end{abstract}

Key words: Pseudomonas cepacia lipase (PCL), transesterification, vinyl acetate, kinetic resolution, optically pure 3-alkanol

\section{Introduction}

Vinyl acetate (VA) is a powerful acetylating reagent for the resolution of enantiomers from chiral compounds by lipase (triacylglycerol hydrolase, EC 3.1.1.3) catalyzed transesterification in organic solvent (1-3): VA irreversibly reacts with the active serine residue in lipase to give the acetyl-enzyme intermediate [Enz-Ac] because vinyl alcohol produced is immediately convert- ed to acetaldehyde by keto-enol tautomerization and this irreversibility serves to acceleration in the reaction rate (1-4). Such a reaction is called "irreversible transesterification" and used for kinetic resolution of various secondary alcohols $(3,5-8)$.

Some information is available on the quantitative analyses of optical resolution data in lipase catalyzed transesterification between VA and chiral compounds with hydroxy group at C-2 position (2-alkanol and its

\footnotetext{
${ }^{*}$ Correspondence to: Hirofumi HiRATA, Department of Bioscience and Technology, School of Engineering, Hokkaido Tokai University, 5-1 Minamisawa, Minami-ku, Sapporo 005-8601, JAPAN

E-mail: hirata@db.htokai.ac.jp
} 
analogue). It has been reported that the reaction is reversible based on the fact that the enantioselectivity $[E$ : the enantiomeric ratio for the homocompetitive reaction, i.e., as the reaction is irreversible] at low conversion is greater than that at high conversion $(>50 \%)$ in Pseudomonas fluorescens lipase (PFL)-catalyzed transesterification with racemic $\beta$-methyl-(2-thiophene)propanol in chloroform (9). Furtheremore it has been reported that the optical resolution data did not fit the previously resolution format $(5,10-12)$ based on the observation: the $E$ value increases with $c$ in the range of below 0.5 in Pseudomonas cepacia lipase (PCL)-catalyzed transesterification with racemic sulcatol, ( \pm )-6methyl-5-hepten-2-ol, in chlorinated solvents (13). In the previous papers on PCL-catalyzed transesterification with 2-alkanol, we reported that the $E$ value showed the maxima at around 0.5 of $c$ in all systems studied (14) and that the reaction of enantiomerically enriched substrate was a powerful strategy for kinetic resolution of chiral compounds with high optical purity (15). So far, no information is available about quantitative analyses of the optical resolution data in kinetic resolution of chiral compounds with $\mathrm{OH}$ group at C-3.

Thus, we selected PCL catalyzed transesterification between VA and 3-alkanol (1) in organic solvent (Scheme 1) and investigated the quantitative analyses of optical resolution data and the resolution of optically pure $(R)$ - and $(S)$-(1) (ee $\geqq 99 \%)$. In this paper, individual 3-alkanol was abbreviated to $\mathrm{X} 3-\mathrm{OH}$, where $\mathrm{X}$ is carbon number of the alcohol and 3- shows the position of hydroxy group, and its acetate was also abbreviated to X3-OAc.

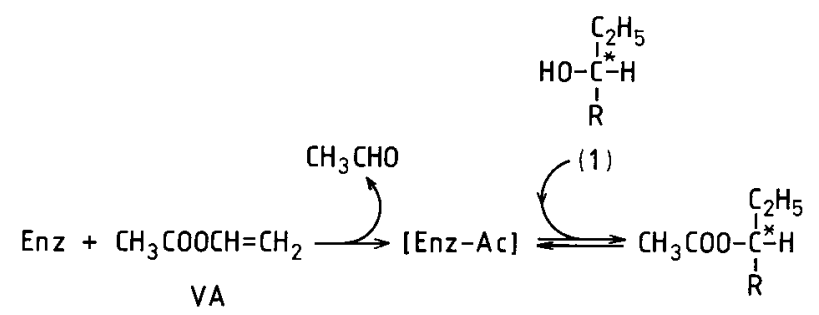

(2)

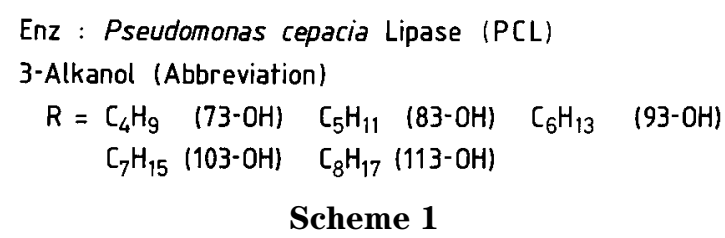

\section{Experimental}

\subsection{Materials}

Vinyl acetate (VA) (GR, Wako Pure Chemical, Osaka) was dried over molecular sieves (3A 1/16, Wako Pure Chemical, Osaka). 3-Alkanol (1) [3-heptanol (73$\mathrm{OH}), 3$-octanol (83-OH), 3-nonanol (93-OH), 3-decanol $(103-\mathrm{OH})$ and 3-undecanol (113-OH)] and $(R)-1-(1-$ naphthyl)ethyl isocyanate (optical purity ee $>99 \%$ ) were purchased from Tokyo Chemical Industry, Tokyo and used without purification. Silica gel (Silica gel 60, 70-230 mesh, Katayama Chemicals, Osaka) was used without treatment or after heating at $200^{\circ} \mathrm{C}$ for $2 \mathrm{~h}$ when the activity was not sufficient for separation of the product (2) and the unreacted substrate (1). Organic solvents were purified by the ordinary method (16). The reaction solvents were dried over molecular sieves before use. Pseudomonas cepacia lipase (PCL) [Lipase PS, $43 \mathrm{U} / \mathrm{mg}$ for hydrolysis and Lipase PS-D (adsorbed on celite), $0.8 \mathrm{U} / \mathrm{mg}$ for the transesterification between VA and 1-phenylethanol] was obtained from Amano Enzyme Inc., Nagoya.

\subsection{Transesterification}

To a stirred solution $(33 \mathrm{~mL})$ containing VA $(1.63 \mathrm{M})$ $\left(1 \mathrm{M}=1 \mathrm{~mol} \mathrm{dm}^{-3}\right)$ and racemic 3-alkanol $(R S)-(\mathbf{1})$ $(0.42-0.63 \mathrm{M})$ at $30^{\circ} \mathrm{C}$ was added PCL (Lipase PS, 100 $\mathrm{mg} / \mathrm{mL}$ or Lipase PS-D, $50 \mathrm{mg} / \mathrm{mL}$ ) and the stirring was continued. The reaction was followed by GC in an appropriate interval and the reaction mixture was filtered at the desired conversion. The enzyme was washed with the solvent $(20 \mathrm{~mL})$ twice. In the case of dioxane, the combined filtrates were poured into water $(300 \mathrm{~mL})$ and the compounds were extracted with hexane $(100 \mathrm{~mL})$ three times. The combined extracts were washed with water $(100 \mathrm{~mL})$ three times, dried over anhydrous sodium sulfate and evaporated. The residue, which contained the product and the unreacted alcohol, was dissolved with hexane $(30 \mathrm{~mL})$ and loaded on the silica gel column (Silica gel $100 \mathrm{~g}, \phi 30 \times 600 \mathrm{~mm}$ ). The compounds were eluted with ethyl acetate-hexane (5:95 vol/vol, $600 \mathrm{~mL})$ and ethanol-hexane (20:80 $\mathrm{vol} / \mathrm{vol}, 400 \mathrm{~mL}$ ). In the cases of other solvents, the filtrates were combined and evaporated. The resulting residue was treated by the same manner as described above.

The fractions (400-550 mL) containing the ester were combined and evaporated, giving $(R)$-1-ethylalkyl 
acetate $[(R)-(2)]$. Yield : 80-95\%. An alkaline solution (1 M KOH dissolved in ethanol containing $10 \mathrm{vol} \%$ of water) $(10 \mathrm{~mL} / \mathrm{g}$-ester) was added to the obtained ester and the mixture was heated at $56^{\circ} \mathrm{C}$ for $40-60 \mathrm{~min}$ and cooled to room temperature or left at room temperature for $12-16 \mathrm{~h}$. A $100 \mathrm{~mL}$ of saturated sodium chloride solution (sat. $\mathrm{NaCl}$ ) was added to the reaction mixture and the compounds were extracted with hexane (30 $\mathrm{mL})$ three times. The combined extracts were washed with sat. $\mathrm{NaCl}(30 \mathrm{~mL})$ three times, dried over anhydrous sodium sulfate and evaporated, giving $(R)$-3-alkanol [(R)-(1)]. Yield: 70-90\% [based on $(R)-(2)]$.

The fractions $(700-1000 \mathrm{~mL})$ were combined and concentrated until crystals of silica gel appeared. A 100 $\mathrm{mL}$ of sat. $\mathrm{NaCl}$ and $5 \mathrm{~mL}$ of $1 \mathrm{M} \mathrm{KOH}$ were successively added to the residue and the compounds were taken up by a similar procedure to that for purification of the ester fractions, giving $(S)$-3-alkanol [(S)-(1)]. Yield: $60-85 \%$.

The resolution from enantiomerically enriched 3alkanols, $(R)$-enriched-(1) (initial optical purity: $\left.e e_{0}=0.52-0.91\right)$ and $(S)$-enriched-(1) $\left(e e_{0}=0.53-0.85\right)$, was carried out in a similar manner as described above. Yields were 85-96, 75-99 and 65-93\% for the ester, its alcohol (based on the ester) and the unreacted alcohol for $(R)$-enriched-(1), and 70-92, 55-90 and 68-99\% for $(S)$-enriched-(1), respectively.

\subsection{Resolution of Optically Pure 3-Alkanol in a Preparative Scale}

$2 \cdot 3 \cdot 1 \quad$ Optically pure $(R)-(\mathbf{1})$

1st Reaction - To a stirred mixture of racemic 3octanol $[(R S)-83-\mathrm{OH}, 0.62 \mathrm{~mol}]$, VA $(1.08 \mathrm{~mol})$ and 1,2-dichloroethane $(500 \mathrm{~mL})$ at $30^{\circ} \mathrm{C}$ was added PCL (Lipase PS-D, $35 \mathrm{~g}$ ) and the stirring was continued. After $2 \mathrm{~h}$ ( $49 \%$ of conversion), the reaction mixture was filtered and the enzyme was washed with 1,2dichloroethane $(200 \mathrm{~mL})$ three times. The filtrates were combined and evaporated. The residue was dissolved in hexane $(500 \mathrm{~mL})$, left at room temperature for $1-3 \mathrm{~h}$, filtered and evaporated. The hexane treatment was carried out twice for removing the crystalline impurities. The refined residue $(100 \mathrm{~g})$ was divided into 5.5-5.6 g portions. Each portion was dissolved with hexane (30 $\mathrm{mL}$ ) and loaded on a silicagel column (Silica gel 100g, $\phi 30 \times 600 \mathrm{~mm})$ and purified by a similar method as desribed above $(\mathbf{2} \cdot \mathbf{2})$. As a result, we obtained enantiomerically enriched $(R)-83-\mathrm{OH}(e e=80 \%$, yield: $84 \%)$ and $(S)-83-\mathrm{OH}$ ( $e e=76 \%$, yield: $82 \%$ ), which were used as the starting materials in the following reactions.

2nd Reaction - A mixture of $(R)-83-\mathrm{OH}(e e=80 \%$, $0.25 \mathrm{~mol})$, VA (0.43 mol), 1,2-dichloroethane (200 mL) and PCL (Lipase PS-D, $14 \mathrm{~g}$ ) was stirred at $30^{\circ} \mathrm{C}$ for 2 $\mathrm{h}(83 \%$ of conversion). The reaction mixture was treated by a similar method as described above (the 1 st reaction and $\mathbf{2} \cdot \mathbf{2}$ ), giving highly enantiomerically enriched $(R)-83-\mathrm{OH}(e e=97 \%)$ in a yield of $82 \%$.

$3 r d$ Reaction - A mixture of $(R)-83-\mathrm{OH}(e e=97 \%$, $0.18 \mathrm{~mol})$, VA $(0.32 \mathrm{~mol}), 1,2$-dichloroethane $(150 \mathrm{~mL})$ and PCL (Lipase PS-D, $10.5 \mathrm{~g}$ ) was stirred at $30^{\circ} \mathrm{C}$ for $100 \mathrm{~min}$ (79\% of conversion). The reaction mixture was treated by a similar method as described above. Finally we obtained optically pure $(R)$-3-octanol with above $99 \%$ of $e e$ in a yield of $80 \%$

Similarly optically pure $(R)$-(1) was resolved from $(R S)-(\mathbf{1})$ in a preparative scale by repeating the transesterification three times. The results were summarized in

Table 1. PCL(Lipase PS) and PCL(Lipase PS-D) were used for the reactions in acetonitrile and 1,2dichloroethane, respectively.

\section{$2 \cdot 3 \cdot 2$ Optically pure $(S)-(\mathbf{1})$}

1 st Reaction was identical to the 1 st reaction for $(R)$ $83-\mathrm{OH}(2 \cdot 3 \cdot 1)$.

2nd Reaction - A mixture of $(S)-83-\mathrm{OH}(e e=76 \%$, $0.25 \mathrm{~mol})$, VA (0.43 mol), 1,2-dichloroethane $(200 \mathrm{~mL})$ and PCL (Lipase PS-D, $14 \mathrm{~g}$ ) was stirred at $30^{\circ} \mathrm{C}$ for 3 h $(30 \%$ of conversion). The reaction mixture was treated by a similar method as described above. The obtained unreacted substrate was colored in yellow or brown and contaminated with a small amount of impurities which was determined by GC. We therefore purified the unreacted substrate as follows: a mixture of the obtained alcohol $(0.20 \mathrm{~mol})$, pyridine $(130 \mathrm{~mL})$ and acetic anhydride $(65 \mathrm{~mL})$ was left at room temperature. After $16 \mathrm{~h}$, the reaction mixture was poured into a stirring sat. $\mathrm{NaCl}(1200 \mathrm{~mL})$ cooled in an ice bath. The resulting solution was acidified with $150 \mathrm{~mL}$ of conc. hydrochloric acid and stirred at $0^{\circ} \mathrm{C}$ for $1 \mathrm{~h}$. The compounds were extracted with hexane $(500 \mathrm{~mL})$ five times. The combined filtrates were washed with sat. $\mathrm{NaCl}(500 \mathrm{~mL})$ five times, dried over anhydrous sodium sulfate and evaporated. The residue was chromatographied and hydrolyzed with $1 \mathrm{M} \mathrm{KOH}$ soln. by a similar method as described above, giving colorless optically pure $(S)-83-\mathrm{OH}$ with above $99 \%$ of $e e$ in a yield of $85 \%$ 
Table 1 Kinetic Resolution of Optically Pure $(R)-(\mathbf{1})$ from $(R S)-(\mathbf{1})$ in a Preparative Scale by PCL-Catalyzed Transesterification with VA in Organic Solvent at $30^{\circ} \mathrm{C}$.

\begin{tabular}{|c|c|c|c|c|c|c|c|c|c|c|c|}
\hline \multirow{2}{*}{$\mathrm{PCL}^{\mathrm{a})}$} & \multirow{2}{*}{ Solv. ${ }^{\text {b) }}$} & \multirow{2}{*}{$(R)-(\mathbf{1})$} & \multicolumn{3}{|c|}{ 1st Reaction ${ }^{\mathrm{c})}$} & \multicolumn{3}{|c|}{ 2nd Reaction } & \multicolumn{3}{|c|}{ 3rd Reaction } \\
\hline & & & $c / \%$ & $\mathrm{Y} / \%$ & $e e_{\mathrm{P}} / \%$ & $c / \%$ & $\mathrm{Y} / \%$ & $e e_{\mathrm{P}} / \%$ & $c / \%$ & $\mathrm{Y} / \%$ & $e e_{\mathrm{P}} / \%$ \\
\hline \multirow[t]{5}{*}{ PS } & $\mathrm{MCN}$ & $73-\mathrm{OH}$ & 52 & 63 & 78 & 75 & 60 & 97 & 85 & 58 & $>99$ \\
\hline & & 83-OH & 54 & 81 & 78 & 77 & 78 & 97 & 88 & 81 & $>99$ \\
\hline & & $93-\mathrm{OH}$ & 54 & 87 & 73 & 80 & 81 & 95 & 85 & 84 & $>99$ \\
\hline & & $103-\mathrm{OH}$ & 53 & 92 & 73 & 75 & 89 & 95 & 80 & 85 & $>99$ \\
\hline & & $113-\mathrm{OH}$ & 55 & 94 & 73 & 75 & 92 & 95 & 82 & 88 & $>99$ \\
\hline \multirow[t]{5}{*}{ PS-D } & DCE & 73-OH & 46 & 65 & 75 & 67 & 66 & 97 & 87 & 64 & $>99$ \\
\hline & & $83-\mathrm{OH}$ & 49 & 84 & 80 & 83 & 82 & 97 & 79 & 80 & $>99$ \\
\hline & & $93-\mathrm{OH}$ & 49 & 92 & 74 & 65 & 83 & 97 & 86 & 83 & $>99$ \\
\hline & & $103-\mathrm{OH}$ & 50 & 97 & 78 & 69 & 90 & 98 & 85 & 86 & $>99$ \\
\hline & & $113-\mathrm{OH}$ & 52 & 99 & 71 & 65 & 94 & 97 & 84 & 92 & $>99$ \\
\hline
\end{tabular}

a) PS: Lipase PS, PS-D: Lipase PS-D. b) MCN: acetonitrile, DCE: 1,2-dichloroethane.

c) $\mathrm{VA}=1.08 \mathrm{~mol}, 73-\mathrm{OH}=0.69 \mathrm{~mol}, 83-\mathrm{OH}=0.62 \mathrm{~mol}, 93-\mathrm{OH}=0.56 \mathrm{~mol}, 103-\mathrm{OH}=0.51 \mathrm{~mol}, 113-\mathrm{OH}=0.47 \mathrm{~mol}$

Lipase $\mathrm{PS}=70.0 \mathrm{~g}$, Lipase PS-D $=35 \mathrm{~g}$. Similar reaction conditions were used in the $2 \mathrm{nd}$ and $3 \mathrm{rd}$ reactions.

$\mathrm{Y}$ : Yield of $(R)-(\mathbf{1})$.

Similarly optically pure $(S)$-(1) was resolved from $(R S)-(\mathbf{1})$ in a preparative scale. The results were summarized in Table 2. PCL(Lipase PS) and PCL(Lipase PS-D) were also used for the reactions in acetonitrile and 1,2-dichloroethane, respectively.

\subsection{Analytical Methods}

GC analysis was done with a Shimadzu 14B
Gaschromatograph equipped with a FID detector. Column: G-100 column, $\phi 1.2 \mathrm{~mm} \times 20 \mathrm{~m}$, film thickness 1 $\mu \mathrm{m}$ (purchased from GL Sciences, Tokyo); Injection and detector temperature : $250^{\circ} \mathrm{C}$; Carrier $\left(\mathrm{N}_{2}\right)$ pressure $: 40 \mathrm{kPa}$ at $80^{\circ} \mathrm{C}$. Column temperature: $70 \rightarrow 120^{\circ} \mathrm{C}, 80$ $\rightarrow 135^{\circ} \mathrm{C}, 95 \rightarrow 150^{\circ} \mathrm{C}, 110 \rightarrow 165^{\circ} \mathrm{C}$, and $125 \rightarrow$ $180^{\circ} \mathrm{C}$ programmed with an increase of $10^{\circ} \mathrm{C} / \mathrm{min}$ for the reaction mixtures of $73-\mathrm{OH}, 83-\mathrm{OH}, 93-\mathrm{OH}, 103-$

Table 2 Kinetic Resolution of Optically Pure $(S)-(\mathbf{1})$ from $(R S)-(\mathbf{1})$ in a Preparative Scale by PCL-Catalyzed Transesterification with VA in Organic Solvent at $30^{\circ} \mathrm{C}$.

\begin{tabular}{|c|c|c|c|c|c|c|c|c|}
\hline \multirow{2}{*}{$\mathrm{PCL}^{\mathrm{a})}$} & \multirow{2}{*}{ Solv. ${ }^{\text {b) }}$} & \multirow{2}{*}{$(S)-(\mathbf{1})$} & \multicolumn{3}{|c|}{ 1st Reaction ${ }^{\mathrm{c})}$} & \multicolumn{3}{|c|}{ 2nd Reaction } \\
\hline & & & $c / \%$ & $\mathrm{Y} / \%$ & $e e_{\mathrm{S}} / \%$ & $c / \%$ & $\mathrm{Y} / \%$ & $e e_{\mathrm{S}} / \%$ \\
\hline \multirow[t]{5}{*}{ PS } & $\mathrm{MCN}$ & $73-\mathrm{OH}$ & 52 & 58 & 84 & 25 & 65 & $>99$ \\
\hline & & $83-\mathrm{OH}$ & 54 & 73 & 91 & 20 & 80 & $>99$ \\
\hline & & 93-OH & 54 & 78 & 86 & 31 & 78 & $>99$ \\
\hline & & $103-\mathrm{OH}$ & 53 & 83 & 84 & 33 & 79 & $>99$ \\
\hline & & $113-\mathrm{OH}$ & 55 & 88 & 89 & 21 & 83 & $>99$ \\
\hline \multirow[t]{5}{*}{ PS-D } & DCE & $73-\mathrm{OH}$ & 46 & 64 & 64 & 43 & 68 & $>99$ \\
\hline & & $83-\mathrm{OH}$ & 49 & 82 & 76 & 30 & 85 & $>99$ \\
\hline & & $93-\mathrm{OH}$ & 49 & 89 & 72 & 35 & 91 & $>99$ \\
\hline & & $103-\mathrm{OH}$ & 50 & 90 & 77 & 31 & 90 & $>99$ \\
\hline & & $113-\mathrm{OH}$ & 52 & 99 & 76 & 35 & 93 & $>99$ \\
\hline
\end{tabular}

a) PS: Lipase PS, PS-D: Lipase PS-D. b) MCN: acetonitrile, DCE: 1,2-dichloroethane.

c) The reaction conditions were described in Table 1. Y : Yield of $(S)-(\mathbf{1})$. 
$\mathrm{OH}$ and $113-\mathrm{OH}$, respectively.

HPLC analysis was carried out with a JASCO (Japan Spectroscopic, Co., Tokyo) Intelligent HPLC equipped with a wavelength variable UV detector. Column: combined two columns of a Finepak SIL (JASCO, particle size: $5 \mu \mathrm{m}, \phi 4.6 \times 250 \mathrm{~mm}$ ) and an Inertsil SIL (GL Sciences, particle size: $5 \mu \mathrm{m}, \phi 4.6 \times 250 \mathrm{~mm}$ ); Mobile phase: dichloromethane containing 0.05 vol\% of methanol; Flow rate: $1.0 \mathrm{~mL} / \mathrm{min}$; Detection wavelength: $254 \mathrm{~nm}$. The enantiomeric excess (ee) of enantiomerically enriched and optically pure 3-alkanols, $(R)$ - and $(S)-(\mathbf{1})$, were determined as the corresponding carbamates (diastereomers) after derivatization with (R)-1-(1-naphthyl)ethyl isocyanate (17).

Optical rotations were measured by a JASCO DIP370 Polarimeter using mercury $405-577$ lines at $20^{\circ} \mathrm{C}$ in chloroform. The specific rotations of optically pure $(R)$ and $(S)-(\mathbf{1})$ were listed in Table 3.

\section{Results and Discussion}

\section{$3 \cdot 1$ Solvent Screening}

According to the optical resolution theory (5, 10-12), the enantioselectivity ( $E$ : the enatiomeric ratio) is expressed as Eq. (1) when the enzymatic reaction is reversible:

$$
\begin{aligned}
E & =\frac{\ln \left[1-(1+K) c\left(1+e e_{\mathrm{P}}\right)\right]}{\ln \left[1-(1+K) c\left(1-e e_{\mathrm{P}}\right)\right]} \\
& =\frac{\ln \left[1-(1+K)\left(c+e e_{\mathrm{S}}\{1-c\}\right)\right]}{\ln \left[1-(1+K)\left(c+e e_{\mathrm{S}}\{1+c\}\right)\right]}
\end{aligned}
$$

where $K$ is the equilibrium constant, $c$ is the extent of conversion, and $e e_{\mathrm{P}}$ and $e e_{\mathrm{S}}$ are the optical purities in enantiomeric excess of the product and the unreacted substrate, respectively. When the reaction is irreversible or the reverse reaction is negligible $(K=0)$, Eq. (1) is reduced to Eq. (2).

$E=\frac{\ln \left[1-c\left(1+e e_{\mathrm{P}}\right)\right]}{\ln \left[1-c\left(1-e e_{\mathrm{P}}\right)\right]}=\frac{\ln \left[(1-c)\left(1-e e_{\mathrm{S}}\right)\right]}{\ln \left[(1-c)\left(1+e e_{\mathrm{S}}\right)\right]}$

If $E$ calculated by Eq. (2) for the reversible reaction, it essentially decreases as $c$ increases (18). However, it has been reported that $E$ can be determined by Eq. (2) in the range of $c$ where the reverse reaction is negligible even though the reaction is reversible $(5,11,12)$.

It has been reported that $E$ is affected by a combination of the structures of solvent and substrate and the solvent hydrophobicity $(\log P)$ in PCL-catalyzed transesterification with tributyrylglycerol (TB) (19-21). We therefore screened more than a dozen solvents for PCLcatalyzed transesterification between VA and (RS)-83$\mathrm{OH}$ at $30^{\circ} \mathrm{C}$. The results were summarized in Table 4 . The $E$ values were determined by Eq. (2). Table 4 shows that 1,2-dichloroethane, acetonitrile and acetone gave higher $E$ than the other solvents. A similsr tendency has been reported in PCL-catalyzed transesterification between TB and secondary alcohol (18-21) and also in the reaction between VA and 2-alkanol (14). Thus, we selected 1,2-dichloroethane and acetonitrile as the reaction solvents and also used hexane as a standard solvent in the following studies.

\begin{tabular}{|c|c|c|c|c|c|c|c|c|}
\hline \multirow[b]{3}{*}{ Substrate } & \multicolumn{8}{|c|}{$\lambda / \mathrm{nm}^{\mathrm{b})}$} \\
\hline & \multicolumn{4}{|c|}{$(R)-(\mathbf{1})^{\mathrm{c})}$} & \multicolumn{4}{|c|}{$(S)-(\mathbf{1})^{\mathrm{d})}$} \\
\hline & 577 & 546 & 435 & 405 & 577 & 546 & 435 & 405 \\
\hline 73-OH & -9.2 & -10.4 & -17.2 & -20.4 & 9.2 & 10.4 & 17.2 & 20.4 \\
\hline 83-OH & -9.6 & -10.8 & -17.9 & -21.2 & 9.5 & 10.8 & 17.8 & 21.2 \\
\hline $93-\mathrm{OH}$ & -8.9 & -10.0 & -16.6 & -19.6 & 8.9 & 10.1 & 16.6 & 19.7 \\
\hline $103-\mathrm{OH}$ & -8.0 & -8.9 & -14.7 & -17.5 & 8.0 & 8.8 & 14.7 & 17.5 \\
\hline $113-\mathrm{OH}$ & -7.5 & -8.5 & -14.0 & -16.6 & 7.5 & 8.5 & 14.0 & 16.6 \\
\hline
\end{tabular}

Table 3 Specific Rotation Values $\left([\alpha]^{/ 0}\right)$ of Optically Pure $(R)-(\mathbf{1})$ and $(S)-(\mathbf{1})^{\mathrm{a})}$.

a) $C=7-8(\mathrm{~g} / 100 \mathrm{~mL})$ in chloroform at $20^{\circ} \mathrm{C}$.

b) Mercury lamp.

c) The optical purity was listed in Table $\mathbf{1}$.

d) The optical purity was listed in Table $\mathbf{2}$. 
Table 4 Solvent Effect on the Enantioselectivity $(E)$ of Optical Resolution by PCL-Catalyzed Transesterification between VA and $(R S)-83-\mathrm{OH}$ at $30^{\circ} \mathrm{C}^{\mathrm{a})}$.

\begin{tabular}{|c|c|c|c|c|c|c|c|c|}
\hline \multirow{2}{*}{ Solvent } & \multicolumn{4}{|c|}{$(R)-83-\mathrm{OH}$} & \multicolumn{4}{|c|}{$(S)-83-\mathrm{OH}$} \\
\hline & $t / \min ^{\mathrm{b})}$ & $c / \%$ & $e e_{\mathrm{P}} / \%$ & $E /-^{\mathrm{c})}$ & $t / \mathrm{h}^{\mathrm{b})}$ & $c / \%$ & $e e_{\mathrm{P}} / \%$ & $E /-^{\mathrm{c})}$ \\
\hline 1,2-Dichloroethane & 130 & 33 & 87 & 23 & 24 & 63 & 99 & 18 \\
\hline Acetonitrile & 160 & 37 & 86 & 22 & 16 & 61 & $>99$ & 23 \\
\hline Acetone & 140 & 35 & 86 & 21 & 24 & 65 & $>99$ & 18 \\
\hline Tetrahydrofuran & 160 & 33 & 85 & 18 & 24 & 65 & $>99$ & 18 \\
\hline Diisopropyl ether & 120 & 35 & 84 & 18 & 24 & 72 & 98 & 9 \\
\hline Hexane & 80 & 33 & 85 & 18 & 24 & 65 & 97 & 12 \\
\hline Octane & 80 & 32 & 85 & 18 & 24 & 65 & 97 & 12 \\
\hline Toluene & 105 & 31 & 84 & 17 & 24 & 69 & $>99$ & 13 \\
\hline Heptane & 80 & 32 & 84 & 17 & 24 & 65 & 97 & 12 \\
\hline Benzene & 100 & 33 & 84 & 16 & 24 & 69 & 99 & 12 \\
\hline Isooctane $^{\mathrm{d})}$ & 70 & 31 & 83 & 16 & 24 & 65 & 98 & 13 \\
\hline Dioxane & 130 & 33 & 82 & 15 & 24 & 67 & $>99$ & 15 \\
\hline Cyclohexane & 70 & 30 & 78 & 11 & 24 & 69 & 99 & 11 \\
\hline Carbon tetrachloride & 75 & 33 & 74 & 10 & 24 & 70 & 99 & 12 \\
\hline
\end{tabular}

a) $[\mathrm{VA}]=1.53 \mathrm{M},[83-\mathrm{OH}]=0.88 \mathrm{M}$ and $\mathrm{PCL}($ Lipase PS $)=100 \mathrm{mg} / \mathrm{mL}$. b) $t$ : the reaction time.

c) Determined by Eq. (2). d) 2,2,4-Trimethylheptane.

\section{$3 \cdot 2$ Quantitative Analyses of Optical Reso- lution Data}

The optical resolution data $\left(e e_{\mathrm{P}}\right.$ and $e e_{\mathrm{S}}$ as functions of $c$ ) were measured for PCL-catalyzed transesterification between VA and $(R S)$-83-OH in 1,2-dichloroethane at $30^{\circ} \mathrm{C}$. The $E$ values were determined by Eq. (2) and the dependence of $E$ on $c$ was invetigated. The results were illustrated in Fig. 1. As shown in Fig. 1B, $E$ incresed with $c$ in the range of below 0.5 . This demonstrates that the transesterification did not obey the previously reported optical resolution format (5, 9-11), neither Eq. (1) nor Eq. (2). The $E$ value sharply decreased with $c$ in the range of above 0.55 (Fig. 1B) due to the reverse reaction. A similar tendency has been reported
A: ee vs. $c$

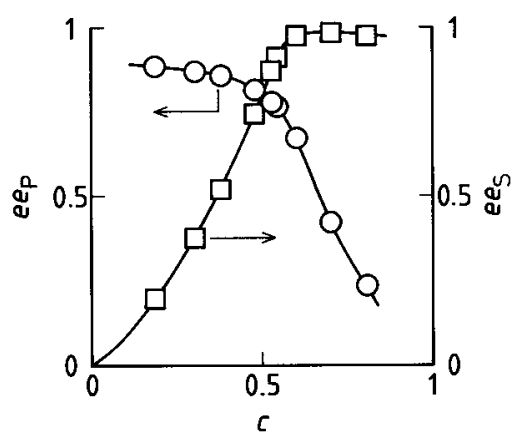

B: $E$ vs. $c$

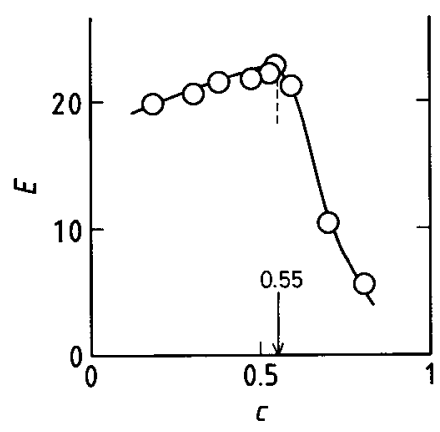

Fig. 1 Plots of ee vs. $c$ and $E$ vs. $c$ for PCL-Catalyzed Transesterification between VA and $(R S)-83-\mathrm{OH}$ in 1,2-Dichloroethane at $30^{\circ} \mathrm{C}$.

$\mathrm{A}: \bigcirc e e_{\mathrm{P}} v s . c, \square e e_{\mathrm{S}} v s . c .[\mathrm{VA}]=1.53 \mathrm{M},[83-\mathrm{OH}]=0.88 \mathrm{M}$ and PCL(Lipase PS $)=100 \mathrm{mg} / \mathrm{mL}$.

B : $E$ vs. $c$. The $E$ values were determined by Eq. (2) using the data in Fig. 1A. 
in PCL-catalyzed transesterification between VA and 2alkanol in various organic solvents (14). In contrast, we observed that the optical resolution data fit Eq. (1) with $E=23$ and $K=0.02$ in the transesterification between triacetylglycerol (TA) and $(R S)-83-\mathrm{OH}$ in 1,2dichloroethane at $30^{\circ} \mathrm{C}$ as for the reversible reaction of TA with $(R S)$-2-octanol in 1,2-dichloroethane $(E=18$ and $K=0.01$ at $\left.30^{\circ} \mathrm{C}\right)(14)$.

In the previous paper, we reported that the extent of conversion of enantiomers in the racemate was calculated by the following equations:

$c_{\mathrm{R}}=c\left(1+e e_{\mathrm{P}}\right)=(1-c)\left(1-e e_{\mathrm{S}}\right)$

and

$c_{\mathrm{S}}=c\left(1-e e_{\mathrm{P}}\right)=(1-c)\left(1+e e_{\mathrm{S}}\right)$

where $c_{\mathrm{R}}$ and $c_{\mathrm{S}}$ are the extents of conversion of $(R)$ and $(S)$ isomers in the racemate (14). Then we invetigated the analysis of optical resolution data by Eqs. (3) and (4) using the data of the transesterification with $(R S)$ 83-OH in Fig. 1A. The results were illustrated in Fig. 2. As shown in Fig. 2A, time courses show that both $c_{\mathrm{R}}$ and $c_{\mathrm{S}}$ increased with the reaction time $(t)$. This suggests that enatiomers in $(R S)-83-\mathrm{OH}$ competitively react with the acetyl-enzyme intermediate ([Enz-Ac] in
Scheme 1) to give the corresponding products. As shown in Fig. 2B, the pseudo first order plot [ln (1-c) $v s . t]$ gave a linearity for the reaction of $(R)-83-\mathrm{OH}$ in $(R S)-83-\mathrm{OH}$, but curveture for $(S)-83-\mathrm{OH}$. This suggests that acetylation of $(S)-83-\mathrm{OH}$ with the acetylenzyme intermediate is suppressed during the reaction. This suppression caused an increase of $E$ in the range of $c<0.5$ (Fig. 1B). A similar tendency has been reported in the transesterification with 2-alkanol (14).

\section{$3 \cdot 3$ Optical Resolution}

Figure 1A demonstrates that the resolution of $(S)-(\mathbf{1})$ with high $e e$ is possible by controlling $c$ of PCL catalyzed transesterification between VA and $(R S)-(\mathbf{1})$. As shown in Table 5, we succeeded in the resolution of $(S)-(\mathbf{1})$ with $e e>95 \%$ as expected.

In contrast, $(R)-(\mathbf{1})$ with $e e>95 \%$ could not be resolved from $(R S)-(\mathbf{1})$ in all cases because of the moderate enantioselectivity (Fig. 1A and Table 5). A simlar resolution has been reported in PCL-catalyzed transesterification between VA and racemic 2-alkanol in organic solvent (15).
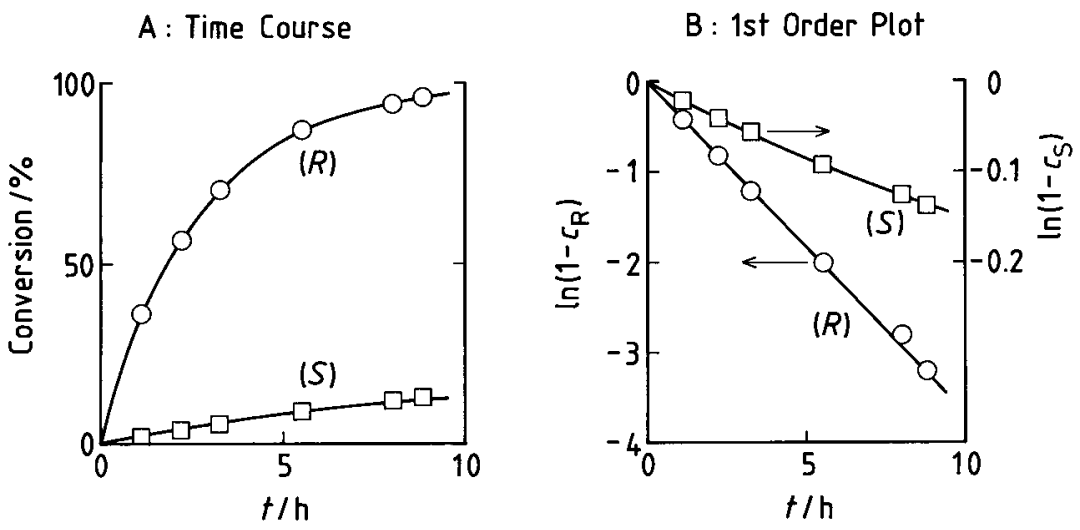

Fig. 2 Time Courses and the First Order Plots of Enantiomers in (RS)-83OH for PCL-Catalyzed Transesterification with VA and $(R S)-83-\mathrm{OH}$ in 1,2-Dichloroethane at $30^{\circ} \mathrm{C}$.

A : Time courses. [VA] $=1.53 \mathrm{M},[83-\mathrm{OH}]=0.88 \mathrm{M}$ and PCL(Lipase $\mathrm{PS})=100 \mathrm{mg} / \mathrm{mL}$. These curves were generated from Eqs. (3) and (4) using the data in Fig. 1A and the time course of the reaction with $(R S)-83-\mathrm{OH}$.

$\mathrm{B}$ : The first order plots. These curves were generated from the data in Fig. 2A. 
Table 5 Resolution of $(R)$ - and $(S)-(\mathbf{1})$ from $(R S)-(\mathbf{1})$ by PCL-Catalyzed Transesterification with VA in Organic Solvent at $30^{\circ} \mathrm{C}$.

\begin{tabular}{rccccccccc}
\hline & \multicolumn{3}{c}{ Hexane $^{\mathrm{a})}$} & \multicolumn{3}{c}{ 1,2-Dichloroethane $\mathrm{e}^{\mathrm{a})}$} & \multicolumn{3}{c}{ Acetonitrile $^{\mathrm{b})}$} \\
\hline$(R)-(\mathbf{1})$ & $c / \%$ & $e e_{\mathrm{P}} / \%$ & $\left.E /-^{\mathrm{c}}\right)$ & $c / \%$ & $e e_{\mathrm{P}} / \%$ & $E /-^{\mathrm{c})}$ & $c / \%$ & $e e_{\mathrm{P}} / \%$ & $\left.E / \mathbf{-}^{\mathrm{c}}\right)$ \\
\hline $73-\mathrm{OH}$ & 44 & 78 & 15 & 46 & 76 & 14 & 41 & 84 & 21 \\
$83-\mathrm{OH}$ & 43 & 83 & 19 & 40 & 85 & 22 & 43 & 84 & 22 \\
$93-\mathrm{OH}$ & 42 & 71 & 10 & 43 & 76 & 13 & 44 & 80 & 17 \\
$103-\mathrm{OH}$ & 43 & 72 & 11 & 43 & 82 & 19 & 45 & 80 & 18 \\
$113-\mathrm{OH}$ & 43 & 63 & 7 & 41 & 77 & 13 & 45 & 80 & 18 \\
\hline$(S)-(\mathbf{1})$ & $c / \%$ & $e e_{\mathrm{S}} / \%$ & $\left.E /-^{\mathrm{c}}\right)$ & $c / \%$ & $e e_{\mathrm{S}} / \%$ & $E /-^{-c)}$ & $c / \%$ & $e e_{\mathrm{S}} / \%$ & $\left.E / \mathrm{-}^{\mathrm{c}}\right)$ \\
\hline $73-\mathrm{OH}$ & 64 & 98 & 15 & 63 & 97 & 14 & 59 & 98 & 21 \\
$83-\mathrm{OH}$ & 63 & 99 & 18 & 62 & 99 & 19 & 61 & $>99$ & 23 \\
$93-\mathrm{OH}$ & 73 & 98 & 9 & 63 & 98 & 16 & 62 & 99 & 21 \\
$103-\mathrm{OH}$ & 64 & 95 & 11 & 62 & 98 & 17 & 63 & $>99$ & 23 \\
$113-\mathrm{OH}$ & 74 & 95 & 7 & 65 & 97 & 12 & 64 & $>99$ & 21 \\
\hline
\end{tabular}

a) $[\mathrm{VA}]=1.63 \mathrm{M},[73-\mathrm{OH}]=0.63 \mathrm{M},[83-\mathrm{OH}]=0.56 \mathrm{M},[93-\mathrm{OH}]=0.51 \mathrm{M},[103-\mathrm{OH}]=0.46 \mathrm{M},[113-\mathrm{OH}]=0.42$ M, PCL(Lipase PS-D) $=50 \mathrm{mg} / \mathrm{mL}$.

b) $[\mathrm{VA}]=1.53 \mathrm{M},[73-\mathrm{OH}]=0.99 \mathrm{M},[83-\mathrm{OH}]=0.88 \mathrm{M},[93-\mathrm{OH}]=0.79 \mathrm{M},[103-\mathrm{OH}]=0.72 \mathrm{M},[113-\mathrm{OH}]=0.66$ $\mathrm{M}, \mathrm{PCL}($ Lipase PS $)=100 \mathrm{mg} / \mathrm{mL}$.

c) Determined by Eq. (2).

\subsection{Kinetic Resolution from Enantiomeri- cally Enriched Substrate}

Kinetic resolution of chiral compounds with $e e>$ $95 \%$ is considered to be practical in a synthetic or industrial sense. For satisfying it, $E$ should be above 150 for the optical resolution at $c=50 \%$ even though the reaction is irreversible [Eq. (2)]. If the reaction is reversible, for example $K=0.02$ in Eq. (1), above 210 of $E$ is required at $c=50 \%$. Such cases are not necessarily obtained for the common enzymatic resolution of certain chiral compound because avilable enzymes and their enantioselectivity are restricted. Thus, kinetic resolution from enantiomerically enriched substrate becomes a powerful strategy for the preparation of optically pure or highly enantiomerically enriched compounds.

When enzymatic reaction with racemate obey Eq. (2), optical purity $\left(e e_{\mathrm{P}}\right)$ of the fast-reacting enantiomer resolved from the reaction of enantiomerically enriched substrate (initial optical purity: $e e_{0}$ ) is predicted by

$\left[1-c^{\prime}\left(\frac{1+e e_{\mathrm{p}}^{\prime}}{1+e e_{0}}\right)\right]=\left[1-c^{\prime}\left(\frac{1-e e_{\mathrm{p}}^{\prime}}{1-e e_{0}}\right)\right]^{E}$

where $c^{\prime}$ is the extent of conversion based on the starting substrate (10). This equation, however, requires that
$E$ is independent of $c$ and $K=0$. Then, we examined the dependence of $E$ on $c$ for PCL-catalyzed transesterification between VA and (RS)-(1). The plots of $\log E v s . c$ were shown in Fig. 3, which demonstrates that the $E$ value increased at first, maximized at around 0.5-0.6 of $c$, and then decreases against $c$ in all systems studied, i.e., $E$ is clearly dependent on $c$. We therefore abandoned the use of Eq. (5) and adopted the previously reported equations using the optical resolution data for predicting optical purities of enantiomers resolved from enantiomerically enriched substrate (15).

\section{$3 \cdot 4 \cdot 1 \quad$ Resolution from $(R)$-enriched-(1)}

The following equations have been reported for predicting the optical purities of enantiomers resolved by the reaction with fast reacting enatiomer enriched substrate with initial optical purity of $e e_{0}$ :

$$
\begin{aligned}
& e e_{\mathrm{P}}=\frac{e e_{0}+e e_{\mathrm{P}}}{1+e e_{0} e e_{\mathrm{P}}} \\
& e e^{\prime}{ }_{\mathrm{S}}=\frac{e e_{0}-e e_{\mathrm{S}}}{1-e e_{0} e e_{\mathrm{S}}} \\
& e e{ }_{\mathrm{S}}>0:(R) \text { configuration } \\
& e e_{\mathrm{S}}<0:(S) \text { configuration }
\end{aligned}
$$

and 


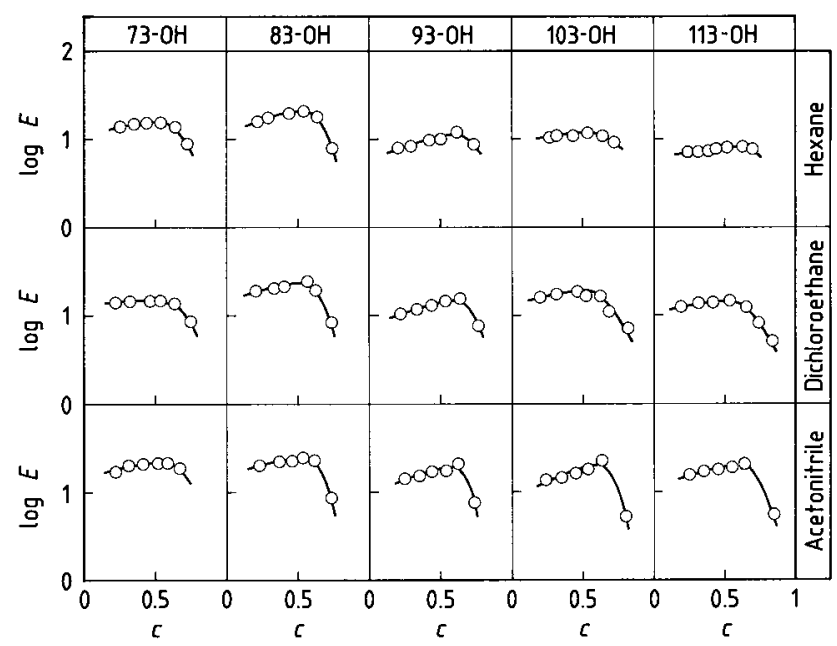

Fig. 3 Plots of $\log E v s . c$ for PCL-Catalyzed Transesterification with VA and (RS)- (1) in Organic Solvent at $30^{\circ} \mathrm{C}$.

For the reaction in hexane and 1,2-dichloroethane:

$[\mathrm{VA}]=1.63 \mathrm{M},[73-\mathrm{OH}]=0.63 \mathrm{M},[83-\mathrm{OH}]=0.56$ $\mathrm{M},[93-\mathrm{OH}]=0.51 \mathrm{M}$,

$[103-\mathrm{OH}]=0.46 \mathrm{M},[113-\mathrm{OH}]=0.42 \mathrm{M}$ and PCL(Lipase PS-D) $=50 \mathrm{mg} / \mathrm{mL}$.

For the reactions in acetonitrile:

$[\mathrm{VA}]=1.53 \mathrm{M},[73-\mathrm{OH}]=0.99 \mathrm{M},[83-\mathrm{OH}]=0.88$ $\mathrm{M},[93-\mathrm{OH}]=0.79 \mathrm{M}$,

$[103-\mathrm{OH}]=0.72 \mathrm{M},[113-\mathrm{OH}]=0.66 \mathrm{M}$ and PCL(Lipase PS $)=100 \mathrm{mg} / \mathrm{mL}$.

The $E$ values were determined by Eq. (2).

$c^{\prime}=\frac{e e_{\mathrm{S}}\left(1+e e_{0} e e_{\mathrm{P}}\right)}{e e_{\mathrm{S}}+e e_{\mathrm{P}}}$

where $e e^{\prime}{ }_{\mathrm{P}}$ and $e e^{\prime}{ }_{\mathrm{S}}$ are optical purities of the product and the unreacted substrate, respectively, and $c$ ' is the extent of conversion based on the enantiomerically enriched substrate (15).

In order to ensure Eqs. (6)-(8) for the prediction, we compared the plots of $e e^{\prime}$ (calc) vs. $c^{\prime}$ (calc) determined by these equations using the resolution data in Fig. 3 with those [ee'(meas) vs. $c^{\prime}$ (meas)] experimentally obtained by the resolution from $(R)$-enriched $93-\mathrm{OH}$ $\left(e e_{0}=0.880,0.749\right.$ and 0.552$)$. The results were illustrated in Fig. 4, which shows an excellent agreement between the calculated and measured plots. Figure 4 also suggests that $(R)-93-\mathrm{OH}$ with $e e_{\mathrm{P}}>95 \%$ can be resolved in a good yield by controlling $c$ of the reaction when $e e_{0}$ is sufficiently high for the resolution. Similar-

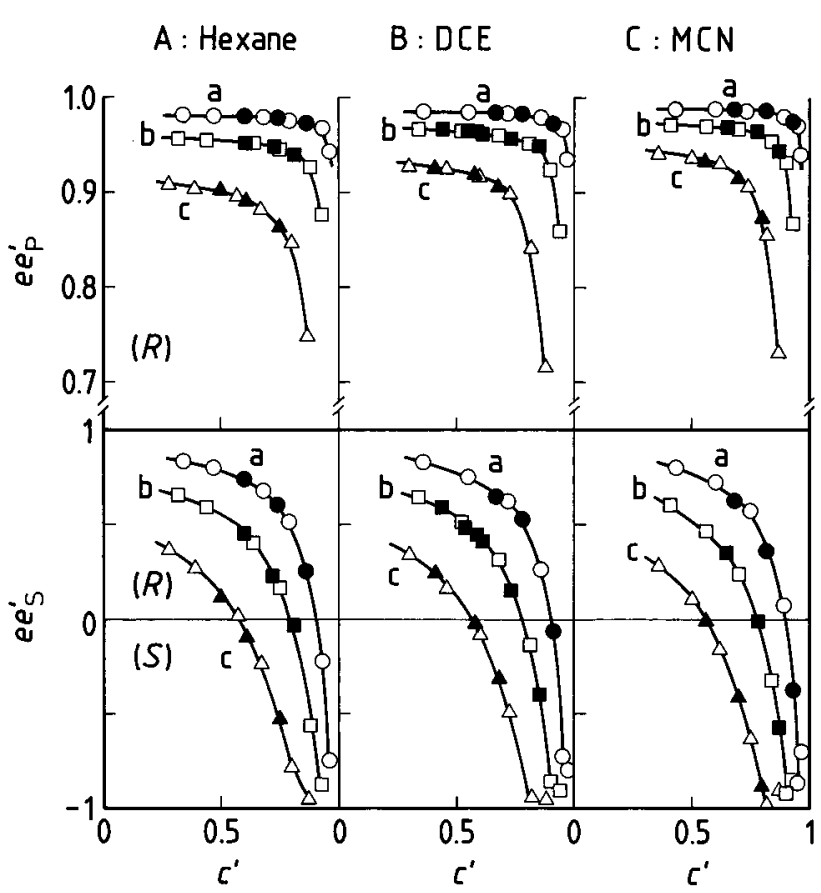

Fig. 4 Plots of ee' $v s$. $c$ for PCL-Catalyzed Transesterification between VA and $(R)$ Enriched 83-OH in Organic Solvent at $30^{\circ} \mathrm{C}$.

Solvent - DCE : 1,2-Dichloroethane, $\mathrm{MCN}$ : Acetonitrile. $e e_{0}$ : (a) 0.880 , (b) 0.749 and (c) 0.522 . $\mathrm{A}, \mathrm{B}:[\mathrm{VA}]=1.63 \mathrm{M},[93-\mathrm{OH}]=0.51 \mathrm{M}$ and PCL(Lipase PS-D) $=50 \mathrm{mg} / \mathrm{mL}$. $\mathrm{C}:[\mathrm{VA}]=1.53 \mathrm{M},[93-\mathrm{OH}]=0.79 \mathrm{M}$ and PCL $($ Lipase PS $)=100 \mathrm{mg} / \mathrm{mL}$. $\bigcirc, \triangle, \square: e e^{\prime}$ (calc) vs. $c^{\prime}$ (calc). $\boldsymbol{O}, \boldsymbol{\Delta}, \mathbf{\square}: e e^{\prime}$ (meas) vs. $c^{\prime}$ (meas).

ly highly enantiomerically enriched $(R)-(\mathbf{1})\left(e e^{\prime}{ }_{\mathrm{P}}>\right.$ 95\%) was obtained from $(R)$-enriched-(1) as shown in Table 6. This table shows that the values of $e e^{\prime}$ (meas) were in an excellent accordance with those of $e e_{\mathrm{P}}$ (calc). The values of $e e^{\prime}$ (meas) were also in agreement with those of $e e$ 's (calc).

\section{$3 \cdot 4 \cdot 2$ Resolution from $(S)$-enriched-(1)}

As shown in Table 5, $(S)-(\mathbf{1})$ with $e e>95 \%$ could be resolved from $(R S)-(\mathbf{1})$ by controlling $c$ of the reaction, but in the expense of low chemical yield because poorly enantiomerically enriched $(R)-(\mathbf{1})$ was obtained in a higher yield than $(S)-(\mathbf{1})$. The use of enantiomerically enriched substrate may avoid this problem. In the previous paper (15), we reported the following equations for 
H. Hirata, M. Ikushima, M. Watanabe et al.

Table 6 Kinetic Resoluton of Highly Enantiomerically Enriched $(R)-(\mathbf{1})$ from $(R)$-enriched-(1) by PCLCatalyzed Transesterification with VA in Organic Solvent at $30^{\circ} \mathrm{C}$.

\begin{tabular}{|c|c|c|c|c|c|c|c|c|c|c|}
\hline \multirow[b]{3}{*}{$(R)-(\mathbf{1})$} & \multirow[b]{3}{*}{$e e_{0} / \%$} & \multicolumn{3}{|c|}{ Hexane $^{a)}$} & \multicolumn{3}{|c|}{ 1,2-Dichloroethane ${ }^{\text {a) }}$} & \multicolumn{3}{|c|}{ Acetonitrile ${ }^{\mathrm{b})}$} \\
\hline & & \multirow{2}{*}{$c^{\prime} / \%$} & \multicolumn{2}{|c|}{$e e_{\mathrm{P}} / \%$} & \multirow{2}{*}{$c^{\prime} / \%$} & \multicolumn{2}{|c|}{$e e_{\mathrm{P}}^{\prime} / \%$} & \multirow{2}{*}{$c^{\prime} / \%$} & \multicolumn{2}{|c|}{$e e_{\mathrm{P}}^{\prime} / \%$} \\
\hline & & & meas & calc $^{\text {c) }}$ & & meas & calc $^{c)}$ & & meas & calc $^{c)}$ \\
\hline \multirow[t]{2}{*}{$73-\mathrm{OH}$} & 73 & 70 & 96 & 96 & 69 & 96 & 96 & 76 & 96 & 96 \\
\hline & 85 & 80 & 98 & 98 & 83 & 98 & 97 & 87 & 98 & 98 \\
\hline \multirow[t]{2}{*}{$73-\mathrm{OH}$} & 67 & 69 & 96 & 96 & 65 & 95 & 96 & 75 & 96 & 96 \\
\hline & 80 & 80 & 97 & 98 & 82 & 98 & 97 & 84 & 97 & 97 \\
\hline \multirow[t]{3}{*}{$93-\mathrm{OH}^{\mathrm{d})}$} & 52 & 50 & 90 & 90 & 58 & 92 & 92 & 56 & 94 & 94 \\
\hline & 75 & 60 & 95 & 95 & 73 & 96 & 96 & 79 & 96 & 96 \\
\hline & 88 & 86 & 97 & 97 & 91 & 97 & 97 & 82 & 99 & 99 \\
\hline \multirow[t]{2}{*}{$103-\mathrm{OH}$} & 73 & 67 & 94 & 95 & 65 & 97 & 97 & 68 & 96 & 97 \\
\hline & 83 & 82 & 96 & 97 & 82 & 98 & 97 & 85 & 97 & 97 \\
\hline \multirow[t]{3}{*}{$113-\mathrm{OH}$} & 71 & 72 & 92 & 92 & 75 & 95 & 96 & 75 & 96 & 96 \\
\hline & 81 & 75 & 95 & 95 & 78 & 96 & 96 & 84 & 97 & 97 \\
\hline & 91 & 90 & 97 & 97 & 90 & 98 & 98 & 91 & 98 & 99 \\
\hline
\end{tabular}

a) $[\mathrm{VA}]=1.63 \mathrm{M},[73-\mathrm{OH}]=0.63 \mathrm{M},[83-\mathrm{OH}]=0.56 \mathrm{M},[93-\mathrm{OH}]=0.51 \mathrm{M},[103-\mathrm{OH}]=0.46 \mathrm{M},[113-\mathrm{OH}]=0.42 \mathrm{M}$, PCL(Lipase PS-D $)=50 \mathrm{mg} / \mathrm{mL}$.

b) $[\mathrm{VA}]=1.53 \mathrm{M},[73-\mathrm{OH}]=0.99 \mathrm{M},[83-\mathrm{OH}]=0.88 \mathrm{M},[93-\mathrm{OH}]=0.79 \mathrm{M},[103-\mathrm{OH}]=0.72 \mathrm{M},[113-\mathrm{OH}]=0.66 \mathrm{M}$, PCL(Lipase PS $)=100 \mathrm{mg} / \mathrm{mL}$.

c) Determined by Eq. (6).

d) From the data in Fig. 3.

kinetic resolution from the slow reacting enantiomer enriched substrate (initial optical purity: $e e_{0}$ ):

$$
\begin{aligned}
& e e^{\prime}{ }_{\mathrm{S}}=\frac{e e_{0}+e e_{\mathrm{S}}}{1+e e_{0} e e_{\mathrm{S}}} \\
& e e^{\prime \prime}=\frac{e e_{0}-e e_{\mathrm{P}}}{1-e e_{0} e e_{\mathrm{P}}} \\
& e e^{\prime}{ }_{\mathrm{P}}>0:(S) \text { configuration } \\
& e e{ }_{\mathrm{P}}<0:(R) \text { configuratior }
\end{aligned}
$$

and

$$
c "=\frac{e e_{\mathrm{S}}\left(1-e e_{0} e e_{\mathrm{P}}\right)}{e e_{\mathrm{S}}+e e_{\mathrm{P}}}
$$

where $e e$ "s and $e e{ }_{\text {p }}$ are optical purities of the product and the unreacted substrate, and $c$ " the extent of conversion based on the enantiomerically enriched substrate.

In order to ensure Eqs. (9)-(11) for the prediction, we invetigated the plots of $e e^{\prime \prime}$ (meas) vs. $c$ "(meas) in PCL catalyzed transesterification with $(S)$-enriched $93-\mathrm{OH}$ $\left(e e_{0}=0.853,0.718\right.$ and 0.530$)$ and compared them with the plots of $e e^{\prime \prime}$ (calc) vs. $c$ "(calc) determined by these equations using the data in Fig. 3. The results were illustrated in Fig. 5. This shows a good agreement between the calculated and measured plots. The higher $c$ " was required for the resolution of optically pure $(S)$ $93-\mathrm{OH}$ by the reaction with $(S)$-enriched $93-\mathrm{OH}$ with lower $e e_{0}$. Figure 5 also suggests that $e e{ }_{\mathrm{s}}>99 \%$ can be attained in a good chemical yield by controlling $c$ of the reaction and $e e_{0}$ of the substrate, which is easily predicted by the $e e^{\prime \prime}$ (calc) $v s . c$ "(calc) plots.

\subsection{Resolution of Optically Pure 3-Alka- nols in a Preparative Scale}

Based on the above observations, we attempted the kinetic resolution of optically pure $(R)$ - and $(S)$-(1) $(e e \geqq 99 \%)$ from $(R S)-(\mathbf{1})$ in a preparative scale by the transesterification in 1,2-dichloroethane and acetonitrile at $30^{\circ} \mathrm{C}$. The results were summarized in Tables 1 and 2. Optically pure $(R)-(\mathbf{1})$ was obtained by repeating the reaction three times and twice for optically pure $(S)-(\mathbf{1})$. The ee values of the resolved alcohols agreed with those determined by Eqs. (6) and (9). This procedure will be a practical method for the resolution of optically pure or highly enantiomerically enriched substrates by enzymatic reactions with a moderate enantioselectivity. 


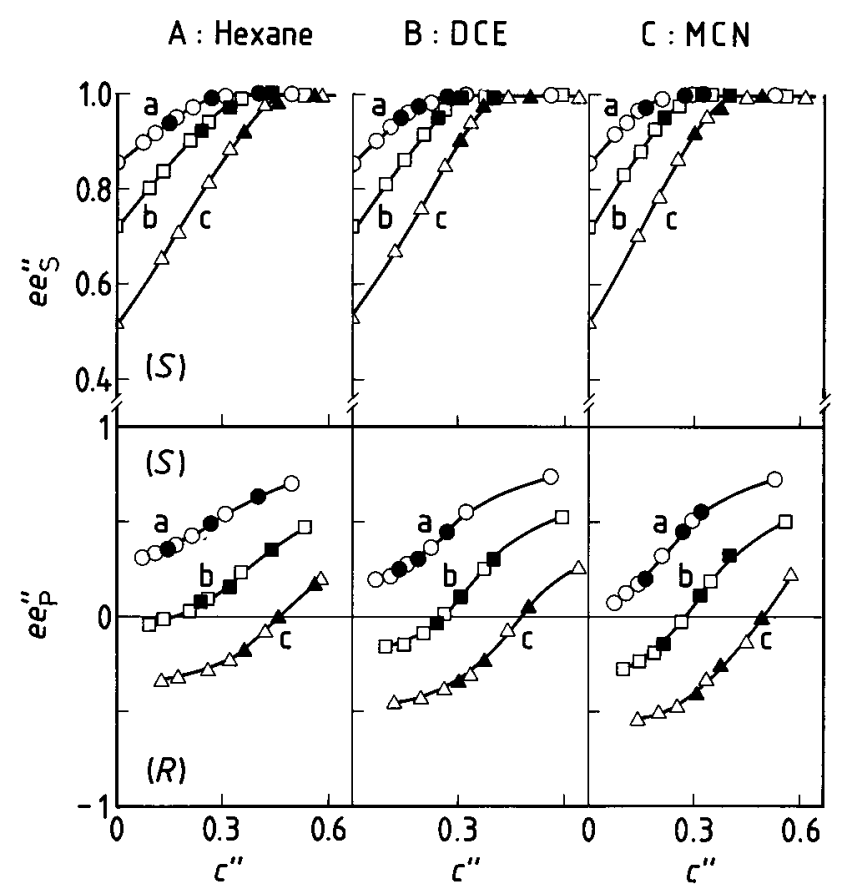

Fig. 5 Plots of $e e$ " vs. $c$ " for PCL-Catalyzed Transesterification between VA and $(S)$ Enriched 83-OH in Organic Solvent at $30^{\circ} \mathrm{C}$

Solvent - DCE: 1,2-Dichloroethane, $\mathrm{MCN}$ : Acetonitrile. $e e_{0}:$ (a) 0.853, (b) 0.718 and (c) 0.530 .
A,B: $[\mathrm{VA}]=1.63 \mathrm{M},[93-\mathrm{OH}]=0.51 \mathrm{M}$ and PCL(Lipase PS-D) $=50$ $\mathrm{mg} / \mathrm{mL}$.

C: $[\mathrm{VA}]=1.53 \mathrm{M},[93-\mathrm{OH}]=0.79 \mathrm{M}$ and PCL(Lipase PS $)=100 \mathrm{mg} / \mathrm{mL}$.

$\bigcirc, \triangle, \square: e e^{\prime \prime(c a l c) ~ v s . ~ c "(c a l c) . ~}$

$\boldsymbol{\gamma}, \boldsymbol{\Lambda}, \boldsymbol{\square}: e e^{\prime \prime(m e a s)} v s . c "($ meas $)$.

\subsection{Specific Rotations}

Finally we measured the specific rotations of optically pure $(R)$ - and $(S)-(\mathbf{1})$. As shown in Table 3, the $[\alpha]$ value of $(R)-(\mathbf{1})$ was negative and positive for $(S)-(\mathbf{1})$. A similar tendency was already reported for 2-alkanol (15). Next, we invetigated the dependence of $[\alpha]=[\alpha](S)=-[\alpha](R)$ on carbon number $(\mathrm{CN})$ of the alcohol and wavelength $(\lambda / \mathrm{nm})$ and compared them with those of 2-alkanol (Figs. 6 and 7). As shown in Fig. 6B, the $[\alpha]$ value of 2-alkanol decreased with $\mathrm{CN}$ of the alcohol. In contrast, the $[\alpha]$ value of 3-alkanol maximized at $\mathrm{CN}=8$ (3-octanol) (Fig. 6A). As shown in Fig. 7, the $[\alpha]$ value increased as $\lambda$ decreased for both

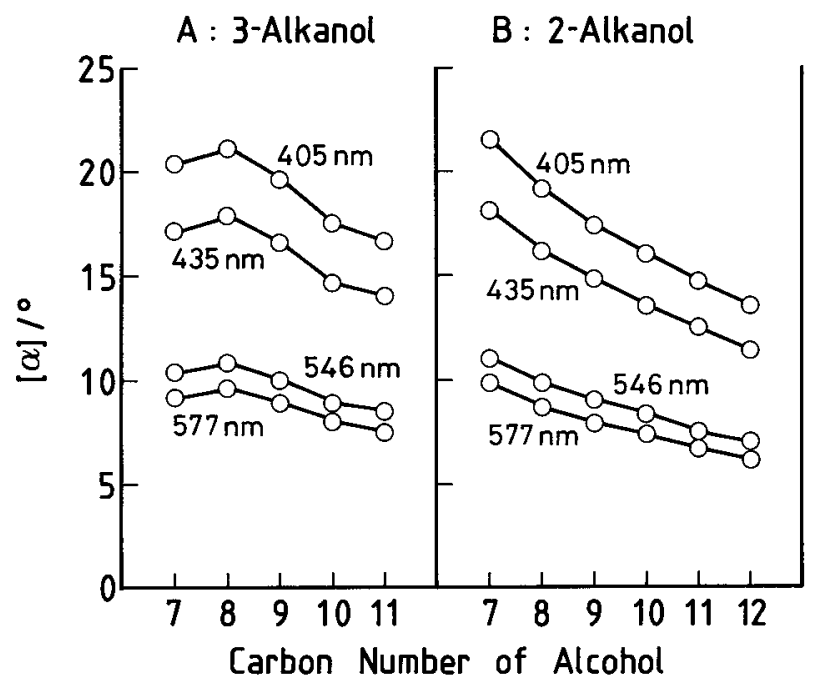

Fig. 6 Plots of $[\alpha]$ vs. Carbon Number of Secondary Alcohol.

$[\alpha]=[\alpha](S)=-[\alpha](R)$.

A: These curves were generated from the data in Table 3.

B: These curves were generated from the data in Ref. (15) and the related experiments.

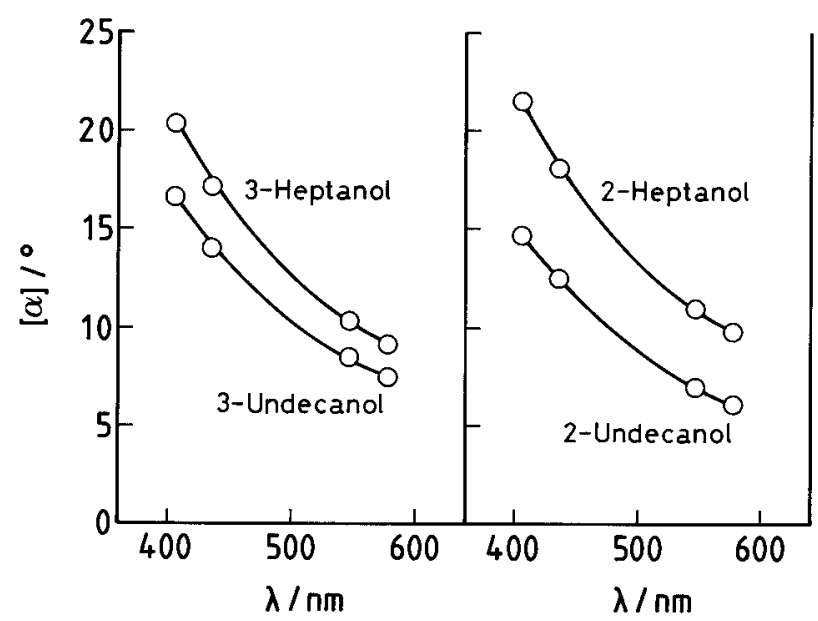

Fig. 7 Plots of $[\alpha] v s$. Wavelength $(\lambda / \mathrm{nm})$.

$[\alpha]=[\alpha](S)=-[\alpha](R)$

Left: These curves were generated from the data in Table 3.

Right: These curves were generated from the data in Ref. (15) and the related experiments. 


\section{H. Hirata, M. Ikushima, M. Watanabe et al.}

alcohols. This recommnds the measurement of $[\alpha]$ at shorter wavelength for the determination of optical purity of secondary alcohols by optical rotation.

\section{References}

1. Y.-F. WANG and C.-H. WONG, Lipase-catalyzed Irreversible Transesterification for Preparative Synthesis of Chiral Glycerol Derivatives, J. Org. Chem., Vol. 53, 3127-3129 (1988).

2. J. HIRATAKAE, M. INAGAKI, T. NISHIOKA and J. ODA, Irreversible and Highly Enantioselective Acylation of 2-Halo-1arylethanols in Organic Solvents Catalyzed by a Lipase from Pseudomonas fluorescens, J. Org. Chem., Vol. 53, 6130-6133 (1988).

3. Y.-F. WANG, J.J. LALONDE, M. MOMONGAN, D.E. BERGBREITER and C.-H. WONG, Lipase-catalyzed Irreversible Transesterification using Enol Esters as Acylating Reagents: Preparative Enantio- and Regioselective Syntheses of Alcohols, Glycerol Derivatives, Sugars, and Organometallics, J. Am. Chem. Soc., Vol. 110, 7200-7205 (1988).

4. M.D. CASTING, B.D. JESO, S. DRAUllard and M. MALLIARD, Enzymatic Reactions in Organic Synthesis: 2. Ester Interchange of Vinyl Esers, Tetrahedron Lett., Vol. 28 953-954 (1987).

5. C.-S. CHEN and Y.-C. LIU, Stereochemical Recognition in Lipase Catalysis, Yukagaku., Vol. 41, 724-733 (1992).

6. E. SANTANIELLO, P. FERRABOSCHI, G. GRISENTI and A.MANZOCCHI, The Biocatalytic Approach to the Preparation of Enantiomerically Pure Chiral Building Blocks, Chem. Rev., Vol. 92, 1071-1140 (1992).

7. K. NAEMURA, Stereoselectivity of Enzymatic Hydroses and Acylations, J. Synth. Org. Chem. Jpn., Vol. 52, 49-57 (1994).

8. K. NAKAMURA and Y. HIROSE, Fitness of Lipases and Substrates in Lipase-catalyzed Resolution, J. Synth. Org. Chem. Jpn., Vol. 53, 668-677 (1995) and the recent papers in Tetrahedron: Asymmetry.

9. M. LUNDH, O. NORDIN, E. HEDENSTROM and H.-E. HOGBERG, Enzyme Catalyzed Irreversible Transesterification with Vinyl Acetate, Tetrahedron: Asymmetry, Vol. 6, 2237-2244 (1995).

10. C.-S. CHEN, Y. FUJIMOTO, G. GIRDAUKAS and C.J. SIH, Quantitative Analyses of Biochemical Kinetic Resolution of Enantiomers, J. Am. Chem. Soc., Vol. 104, 7294-7299 (1982).

11. C.-S. CHEN, S.-H. WU, G. GIRDAUKAS and C.J. SIH, Quantitative Analyses of Biochemical Kinetic Resolution of Enan- tiomers. 2. Enzyme-catalyzed Esterification in Water-Organic Solvent Biphasic Systems, J. Am. Chem. Soc., Vol. 109, 28122817 (1987).

12. C.-S. CHEN and C.J. SIH, General Aspect and Optimization of Enantioselective Biocatalysis in Organic Solvents: The Use of Lipases, Angew. Chem. Int. Ed. Engl., Vol. 28, 695-707 (1989).

13. F. SECUNDO, G. OTTOLINA, S. RIVA and G. CARREA, The Enantioselectivity of Lipase PS in Chlorinated Solvents Increases as a Function of Substrate Conversion, Tetrahedron: Asymmetry, Vol. 8, 2167-2173 (1997).

14. M. OHNO, N. KAMO, T. KITAMOTO, N. YAMAZATO, N. HOSHIBA, M. MAYAMA and H. HIRATA, Kinetic Studies on the Optical Resolution of 2-Alkanol by Pseudomonas cepacia Lipase Catalyzed Transesterification with Vinyl Acetate in Organic Solvent, J. Oleo Sci., Vol. 51, 643-653 (2002).

15. H. HIRATA, M. OHNO, K. KAWAUCHI, M. MAYAMA, Y.-W. CHEN, H. YANAGISHITA and N. KAMO, Kinetic Resolution of Enantiomers in Enantiomerically Enriched 2-Alkanol by Pseudomonas cepacia Lipase Catalyzed Transesterification with Vinyl Acetate in Organic Solvent, J. Oleo Sci., Vol. 52, 99-108 (2003).

16. J.A. RIDDICK and W.B. BUNGER, Organic Solvent, IV, Wiley-Interscience, New York, London, Sydney, Toronto (1970).

17. H. HIRATA, T. YAMASHINA, K. HIGUCHI, K. SAKAKI and I. IIDA, Determination of Enantiomer Content of Secondary Alkanol as Diastereomeric $N$-[1-(1-Naphthyl)ethyl]carbamate by Normal Phase HPLC, Yukagaku, Vol. 40, 995-1001 (1991).

18. H. HIRATA, M. MAYAMA, N. INADA, K. YAMADA, H. YANAGISHITA and M. SUGIURA, Kinetics on the Optical Resolution of 2-Octanol in Tributyrylglycerol by Lipase-Catalyzed Transesterification, Yukagaku, Vol. 44, 1067-1074 (1995).

19. H. HIRATA, M. MIYAGISHI and M. MAYAMA, Enantioselectivity of Lipase Catalyzed Transesterification between Tributyrylglycerol and 2-Octanol in Organic Solvents, Nippon Kagaku Kaishi, Vol. 1998, 113-118 (1998).

20. H. HIRATA, M. MAYAMA, H. YANAGISHITA and M. SUGIURA, Effects of Solvent and Substrate on Enantioselectivity in Pseudomonas cepacia Lipase Catalyzed Transesterification between Tributyrylglycerol and 2-Alkanol in Organic Solvent, $J$. Jpn. Oil Chem. Soc., Vol. 47, 1217-1223 (1998).

21. H. HIRATA, M. MAYAMA, M. OHNO, N. KAMO and H. YANAGISHITA, Enantioselectivity in Pseudomonas cepacia Lipase Catalyzed Transesterification between 1,2,3-Propanetriyl Tributyrate and Secondary Alcohol, Nippon Kagaku Kaishi, Vol. 2002, 147-154 (2002). 